\title{
Racial and ethnic diversity: Information exchange
}

\author{
By Susana Hinojosa \\ Chair, ACRL Racial and Ethnic Diversity Committee
}

- Has your Library developed or taken part in programs that promote cultural awareness? We are particularly interested in receiving information about programs that would serve as good role models for libraries now interested in participation in such training. A subcommittee of the ACRL Racial and Ethnic Diversity Committee has been working since ALA Midwinter on gathering information on multicultural awareness training programs taking place in libraries. The co-chairs of this subcommittee, Kriza Jennings (United Theological Seminary) and Vivian Sykes (UC Santa Cruz), have gathered an impressive amount of material but would appreciate information about programs that are now in the planning stages or that are considered excellent models. The goal is to enable the committee to develop initiatives, recommendations, and training models of use to libraries. Information can be sent to: Vivian Sykes, McHenry Library, UC Santa Cruz, Santa Cruz, CA 95064 by July 31; after August 1, send material to: Vivian Sykes, c/o Library Director's Office, Library, University of Michigan, Ann Arbor, MI 48109-1205.

- REFORMA has passed a Resolution Regarding the Observance of the Arrival of Columbus in the Western Hemisphere. It calls attention to the fact that Columbus's arrival was also the beginning of the end for many native cultures and that there was brutal exploitation. REFORMA feels that there should be balanced attention to Columbus. We have noticed that many libraries are gearing up for celebrations focusing only on the popular "sanitized" account of Columbus's arrival. For a copy of the resolution contact: Ron Rodriguez, President, REFORMA, Chicano Research Center, P.O. Box 34080 , University Library, CSU Fullerton, Fullerton, CA 92634 or call 714-773-2537.

- REFORMA has contributed a position paper on cultural diversity integration into library schools' curriculums (authored by Ron Rodriguez of REFORMA and Albert Milo of Fullerton (CA) Public Library) to the ALISE Special Committee on Ethnic, Multicultural, and Humanities Concerns. Future plans for this ALISE committee include the possibility of a workshop on this topic at the 1992 ALISE Annual Conference. Copies of this position paper are available from Ron at the above address.

- The Annual Medical Library Association Conference, held in San Francisco, June 1-6, 1991, featured a session called "Cultural Diversity Issues in Librarianship" presented by the MLA Relevant Issues Section and the Medical Library Education Section (sponsored by Rittenhouse Book Distributors, Inc.). Papers were presented on the following topics: "Education and Diversity" by Gwendolyn S. Cruzat (SLIS, University of Michigan); "Modern Racism and Building Multiracial and Multicultural Environments" by Edith Fisher (president, TENGE Enterprises); "Recruitment and Advancement of Minority Librarians" by Susana Hinojosa (UC Berkeley); and "Diversity: Its Impact on the Development of Library Services" by Janice Koyama (UC Berkeley). The session was taped. For further information contact: Judy Bube, Program Chair, MLA Relevant Issues Section, Biomedical Library, UC Irvine, Irvine, CA 92717.

Note: Items of a practical nature that highlight programs, reports, and activities in academic 7 brarianship and ACRL that address racial and multicultural issues are especially needed for this column. Please forward items to: Susana Hinojosa, Moffitt Undergraduate Library, UC Berkeley, Berkeley, CA 94720; e-mail: shinojos@library. berkeley.edu; fax: (415) 643-7891

\section{WHCLIS open to public}

The White House Conference is open to the public. Advanced registration for observers is $\$ 55$, on-site registration is $\$ 70$. Observers needing assistance in travel and lodging may contact Carlson Travel Network, (800) 444-9848. In Maryland, Virginia, and D.C. call (301) 7386550 . For registration materials, call the Conference office at (800) 942-5472. 